\title{
PERFIL EPIDEMIOLÓGICO DOS PACIENTES ATENDIDOS DEVIDO A ACIDENTES OFÍDICOS NO NORTE DO BRASIL, REGIÃO AMAZÔNICA, NO PERÍODO DE 2009 A 2019
}

\section{ARTIGO ORIGINAL}

CARNEIRO, Larissa Queiroz Costa ${ }^{1}$

BARBOSA, Isabela Menezes ${ }^{2}$

CARDOSO, Igor de Souza ${ }^{3}$

DIAS, Cláudio Alberto Gellis de Mattos ${ }^{4}$

OLIVEIRA, Euzébio de ${ }^{5}$

DENDASCK, Carla Viana ${ }^{6}$

FECURY, Amanda Alves ${ }^{7}$

${ }^{1}$ Discente do Curso de Medicina da Universidade Federal do Amapá (UNIFAP).

2 Discente do Curso de Medicina da Universidade Federal do Amapá (UNIFAP).

${ }^{3}$ Discente do Curso de Medicina da Universidade Federal do Amapá (UNIFAP).

${ }^{4}$ Biólogo, Doutor em Teoria e Pesquisa do Comportamento, Professor e pesquisador do Programa de Pós-Graduação em Educação Profissional e Tecnológica (PROFEPT), Instituto Federal do Amapá (IFAP).

5 Biólogo, Doutor em Doenças Topicais, Professor e pesquisador do Curso de Educação Física da Universidade Federal do Pará (UFPA).

6 Teóloga, Doutora em Psicanálise, pesquisadora do Centro de Pesquisa e Estudos Avançados- CEPA.

${ }^{7}$ Biomédica, Doutora em Doenças Tropicais, Professora e pesquisadora do Curso de Medicina da Universidade Federal do Amapá (UNIFAP). 
CARNEIRO, Larissa Queiroz Costa. Et al. Perfil epidemiológico dos pacientes atendidos devido a acidentes ofídicos no norte do Brasil, Região Amazônica, no período de 2009 a 2019. Revista Científica Multidisciplinar Núcleo do Conhecimento. Ano 05, Ed. 09, Vol. 03, pp. 47-59. Setembro de 2020. ISSN: 2448-0959, Link de acesso: https://www.nucleodoconhecimento.com.br/saude/acidentes-ofidicos

\section{RESUMO}

Os acidentes ofídicos são significativo problema de saúde pública em âmbito mundial, devido tanto a sua frequência, quanto a sua morbimortalidade. No Brasil, durante os anos de 2009 a 2019 tiveram 313.139 casos registrados, dos quais 151.565 ocorreram na Região Norte, deixando explícita a importância do estudo desse agravo na referida Região. O objetivo do presente estudo é determinar o perfil epidemiológico dos pacientes acometidos (idade e sexo), do próprio acidente (UF, mês, ano, tempo para atendimento) e do gênero da serpente dos acidentes ocorridos na região Norte do Brasil. Dados secundários foram obtidos através do acesso ao acesso ao Departamento de Informática do Sistema Único de Saúde do Brasil (DATASUS), no endereço eletrônico www.datasus.gov.br, no Sistema de Informações Hospitalares $\mathrm{SIH} / \mathrm{SUS}$. Constatou-se que os acidentes ocorreram, principalmente, em área rural, com homens, em idade socioeconomicamente ativa, ocasionados por serpentes do gênero Bothrops. Diversos casos puderam ser classificados como acidente de trabalho, estes poderiam ser evitados ou minimizados com orientações e equipamentos de proteção individual adequados.

Palavras- chave: Acidente ofídico, Ofidismo, Serpente, Amazônia.

\section{INTRODUÇÃO}

Os acidentes causados por serpentes peçonhentas representam significativo problema de Saúde Pública, especialmente em países tropicais pela frequência com que ocorrem e pela morbi-mortalidade que ocasionam. Tanto que os acidentes por animais peçonhentos são classificados pela Organização Mundial de Saúde como doença tropical negligenciada, o que implica em dizer que eles são mais comuns em 
locais de difícil acesso e em populações com baixo nível socioeconômico (PINHO et al., 2001; WHO, 2019).

Animais peçonhentos são definidos por possuírem glândulas venenosas associadas a mecanismos de injeção ativa do veneno, como dentição oca, ferrões e aguilhões. Sendo representados por diversos gêneros e espécies de cobras, além de escorpiões, quilópodes e aracnídeos. Diferenciam-se de animais venenosos passivos como taturanas, sapos e lagartos, que possuem mecanismos de envenenamento por contato, ingestão e compressão (GUTIÉRREZ et.al., 2017).

Sendo assim, os acidentes ofídicos são classificados também como emergência médica, e como tal, podem rapidamente levar a vítima a morte. Os efeitos do envenenamento podem ser locais ou sistêmicos, e isso depende da espécie da cobra e das toxinas presentes no veneno (WHO, 2019).

Em âmbito mundial, cerca de 7.400 pessoas são picadas por serpentes diariamente, entretanto, o dado mais relevante é que, desses casos, de 220 a 380 pessoas evoluem a óbito. Totalizando aproximadamente 140 mil mortes ao ano no mundo (PINHO et al., 2001; WHO, 2019).

No Brasil, desde 1986, é compulsória a notificação de tais acidentes, os quais se encontram no Sistema de Informações de Notificação de Agravos (SINAN), onde foram reportadas cerca de 30 mil intercorrências com picadas de cobras todos os anos na última década, com notória contribuição da região Norte do país nesses números (WEISS; PAIVA, 2017).

\section{OBJETIVO}

Traçar o perfil epidemiológico dos pacientes atendidos devido a acidentes ofídicos no Norte do Brasil, região Amazônica, no período de 2009 a 2019, identificando as variáveis que influenciaram na ocorrência desses acidentes. 


\section{MÉTODO}

Foi realizado um estudo analítico e retrospectivo, utilizando como instrumento de coleta de dados as planilhas geradas através da página eletrônica do Departamento de Informática do Sistema Único de Saúde (DATASUS) em www.datasus.saude.gov.br obedecendo as seguintes etapas respectivamente: "Acesso à informação"; "Informações em saúde (TABNET)"; "Epidemiológicas e Morbidade"; "Doenças e Agravos de Notificação" - de 2007 em diante; "Acidentes por Animais Peçonhentos" e; por fim, a opção "Brasil por região, UF e municípios".

As planilhas resultantes agregaram as seguintes variáveis disponibilizadas pelo SINAN em http://tabnet.datasus.gov.br/cgi/tabcgi.exe?sinannet/animaisp/bases/ animaisbrnet.def: Região (Norte); Unidade da Federação (Acre; Amapá; Amazonas; Pará; Rondônia; Roraima e Tocantins), ano e mês do acidente; tempo decorrido entre o acidente e 0 atendimento médico e; o tipo de serpente envolvida. Sendo realizada a correlação entre o ano em que ocorreram os acidentes e os demais fatores de interesse em relação a estes. Além disso, em toda a pesquisa, foi selecionado "Serpente", no tópico, "Tipo de acidente".

\section{RESULTADOS}

No período entre janeiro de 2009 e dezembro de 2019 foram registrados 313.139 casos de acidentes ofídicos no Brasil, sendo que 101.565 desses casos ocorreram na Região Norte. A distribuição dos casos notificados por ano na referida região encontrase representado na figura 1. 
Figura 1. Mostra a quantidade de casos de acidentes ofídicos na região Norte do Brasil entre os anos de 2009 e 2019.

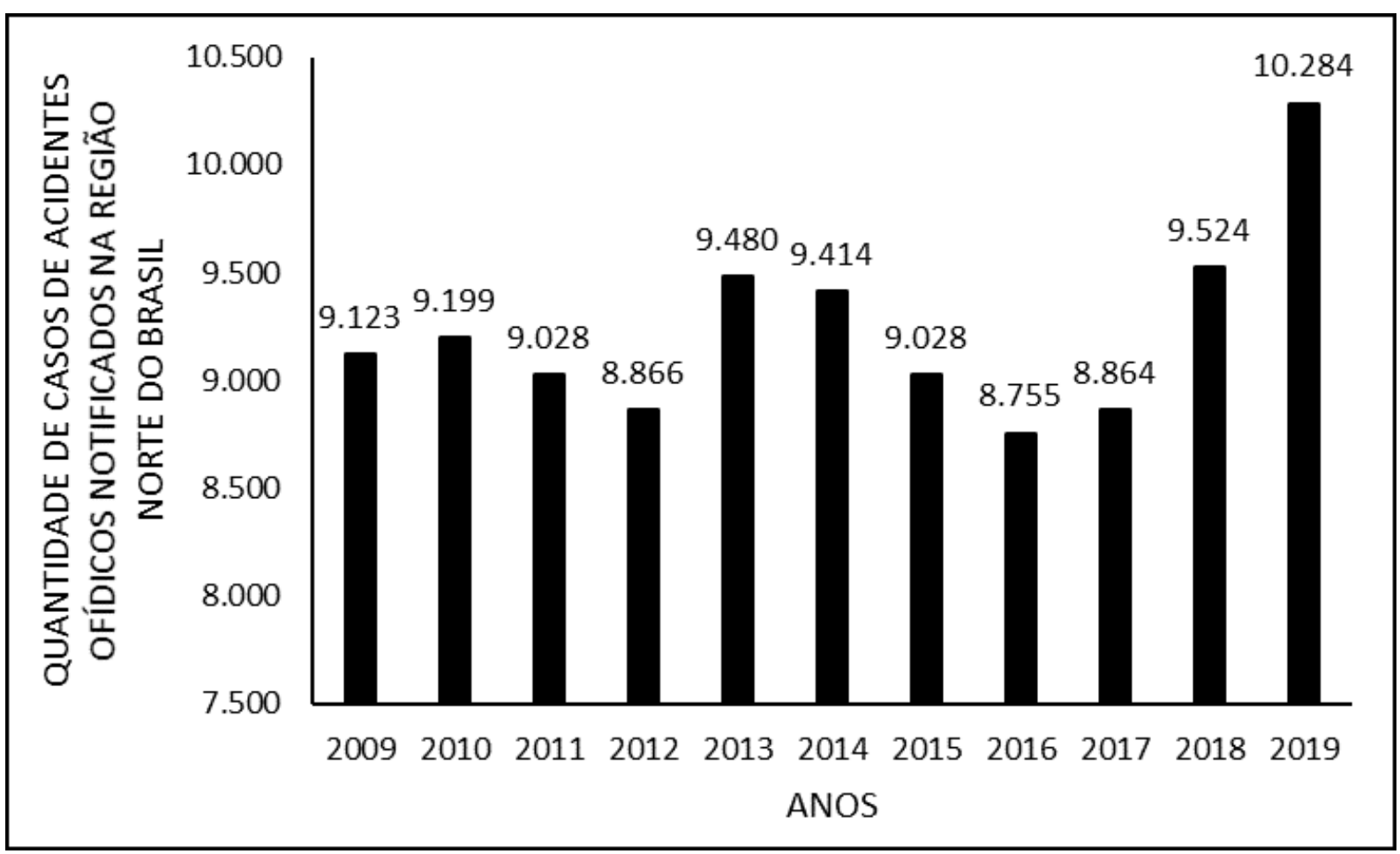

$\mathrm{Na}$ década estudada consegue-se ainda inferir a distribuição dos casos por Unidade Federativa, mostrando que apesar dos acidentes acontecerem em uma mesma Região, existe uma considerável disparidade no número de notificações. Evidenciado, por exemplo, pelo fato de que Roraima registrou 3.960 casos (3,90\%); enquanto que Pará obteve 54.236 (53,40\%), no mesmo período. Foram obtidos também os dados dos outros estados da Região Norte nessa mesma década, a saber: Rondônia com 5.616 (5,53\%); Acre com 5.216 (5,14\%); Amapá com 5.381 (5,30\%; Tocantins com $9.173(9,03 \%)$ e; Amazonas com 17.983 (17,71\%) casos notificados (figura 2). 
Figura 2. Mostra a quantidade de casos de acidentes ofídicos na região Norte do Brasil entre os anos de 2009 e 2019, por estados do Brasil.

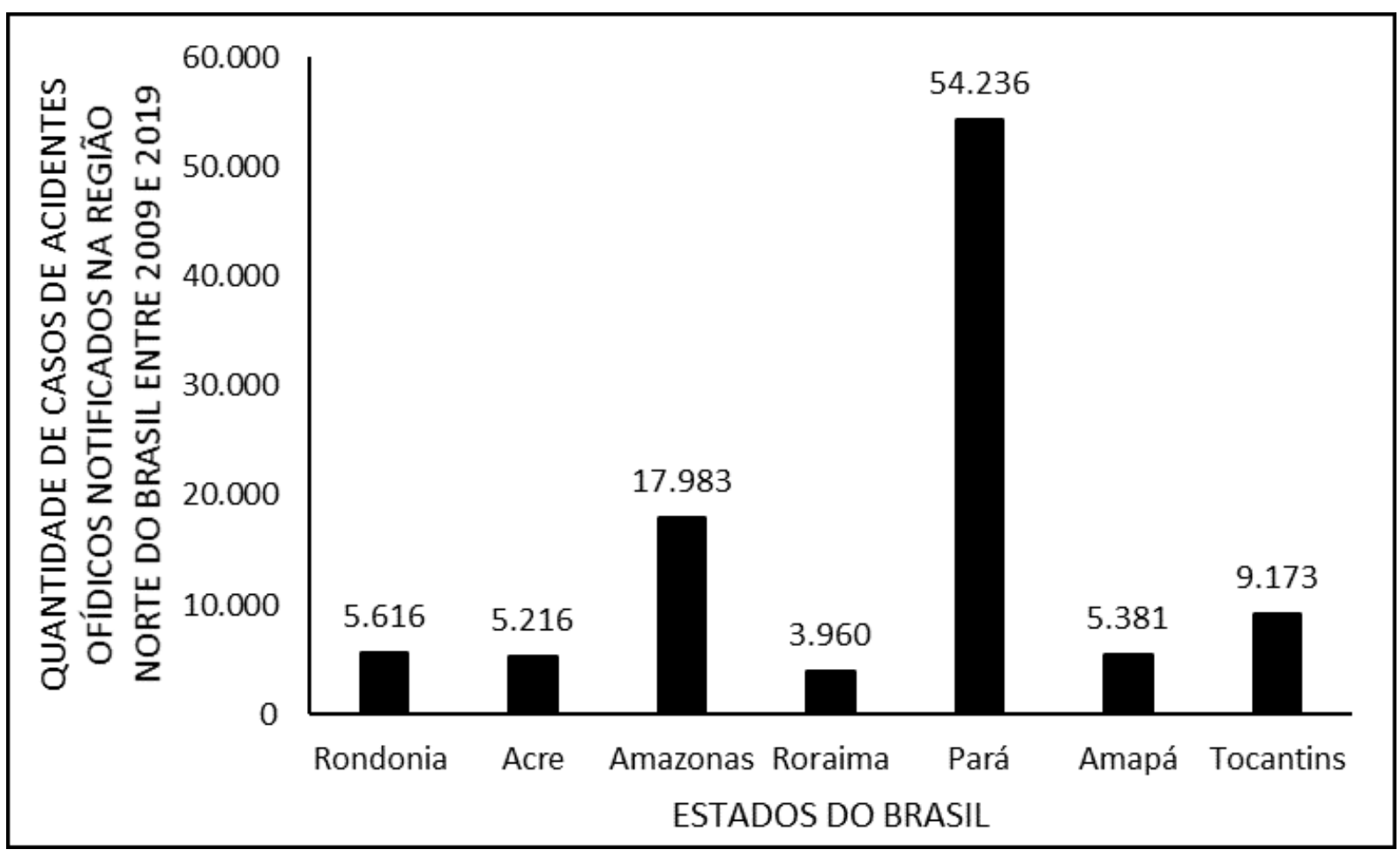

No que tange à caracterização dos acidentes em relação ao meio, verificou-se a distribuição dos acidentes de acordo com os meses do ano. Em janeiro ocorreram 10.351 casos; fevereiro foram 10.013; março 10.876; abril 9.880; maio 9.734, com quedas significativas a partir de junho que apresentou 8.270 casos; já em julho foram 7.537 e; seguido por agosto com 6.494. Atingindo o menor número de casos em setembro com 5.967, porém com o aumento progressivo dos casos a partir de outubro com 6.860; novembro 7.667 e dezembro com 7.916, conforme demonstrado de forma percentual na figura 3 . 
Figura 3. Mostra a quantidade de casos de acidentes ofídicos na região Norte do Brasil entre os anos de 2009 e 2019, por meses do ano.

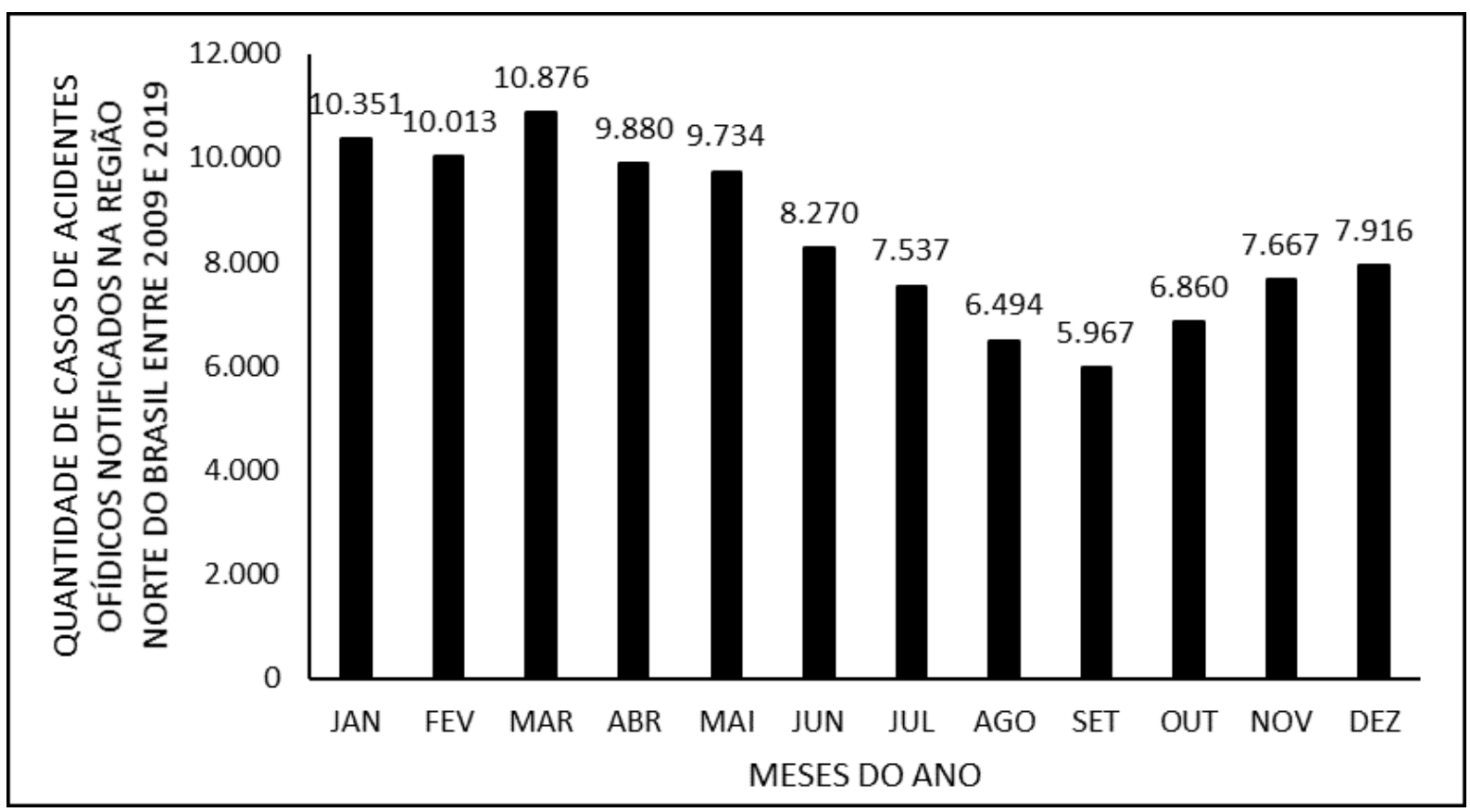

Desses casos notificados, foram aferidos ainda alguns outros dados de fundamental importância para a caracterização epidemiológica do perfil das pessoas que sofreram acidentes ofídicos nesse período. Tais como o sexo e a idade das vítimas.

Em relação a distribuição entre os gêneros dos acidentados é possível constatar que dos 101.565 casos, 21.409 (21,1\%) ocorreram com mulheres, enquanto 80.143 $(78,9 \%)$ com homens. Na figura 4, consegue-se visualizar a distribuição dos casos por gênero, por ano (2009 a 2019) na Região Norte. Na figura 5 pode-se observar a distribuição percentual dos acidentes em relação ao sexo da vítima sendo organizados de acordo com a UF de notificação, abordando todo o período de 2009 a 2019. 
Figura 4. Mostra a quantidade de casos de acidentes ofídicos na região Norte do Brasil entre os anos de 2009 e 2019, por gênero.

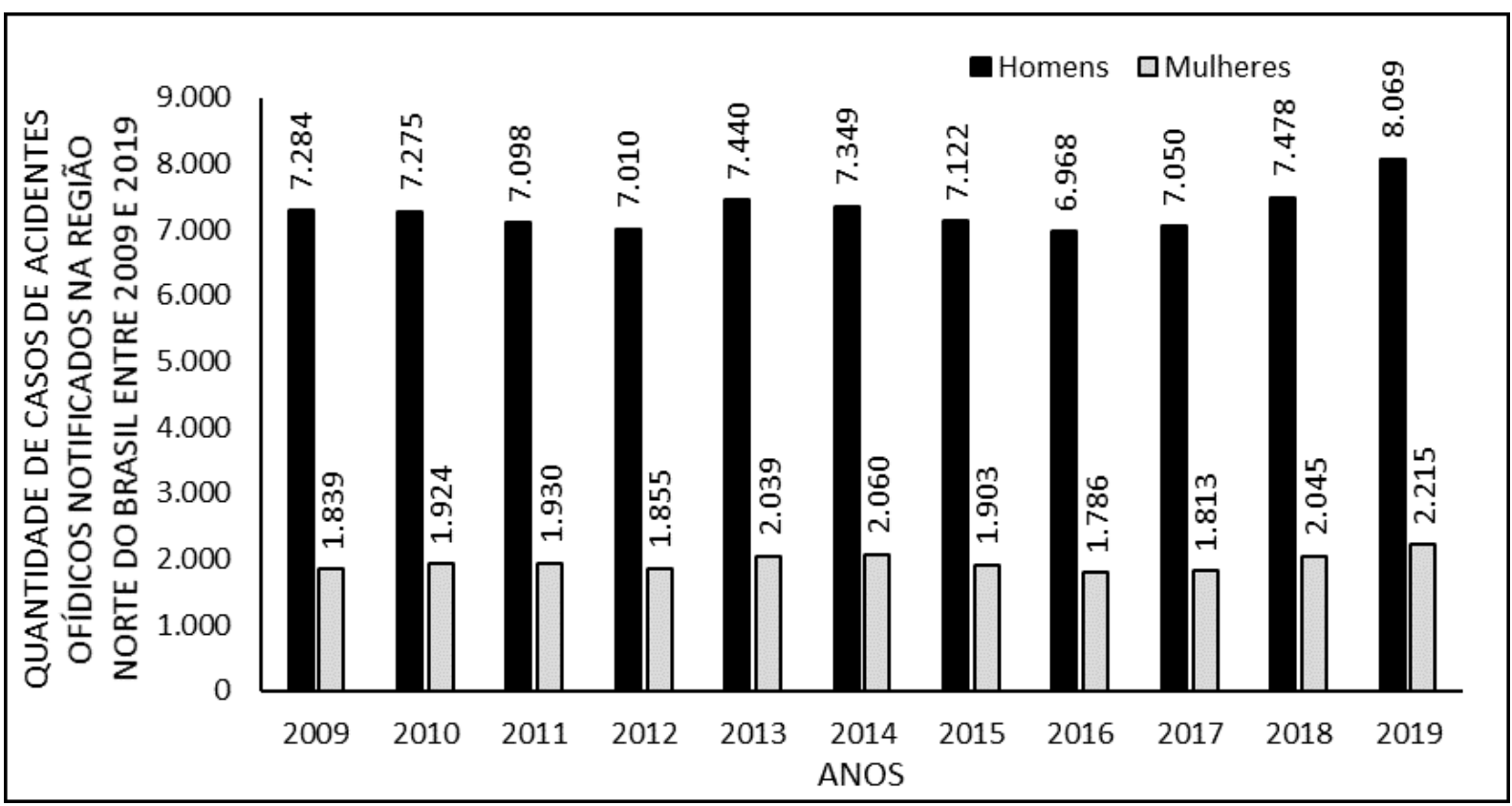

Figura 5. Mostra a quantidade de casos de acidentes ofídicos na região Norte do Brasil entre os anos de 2009 e 2019, por gênero, por estados do Brasil.

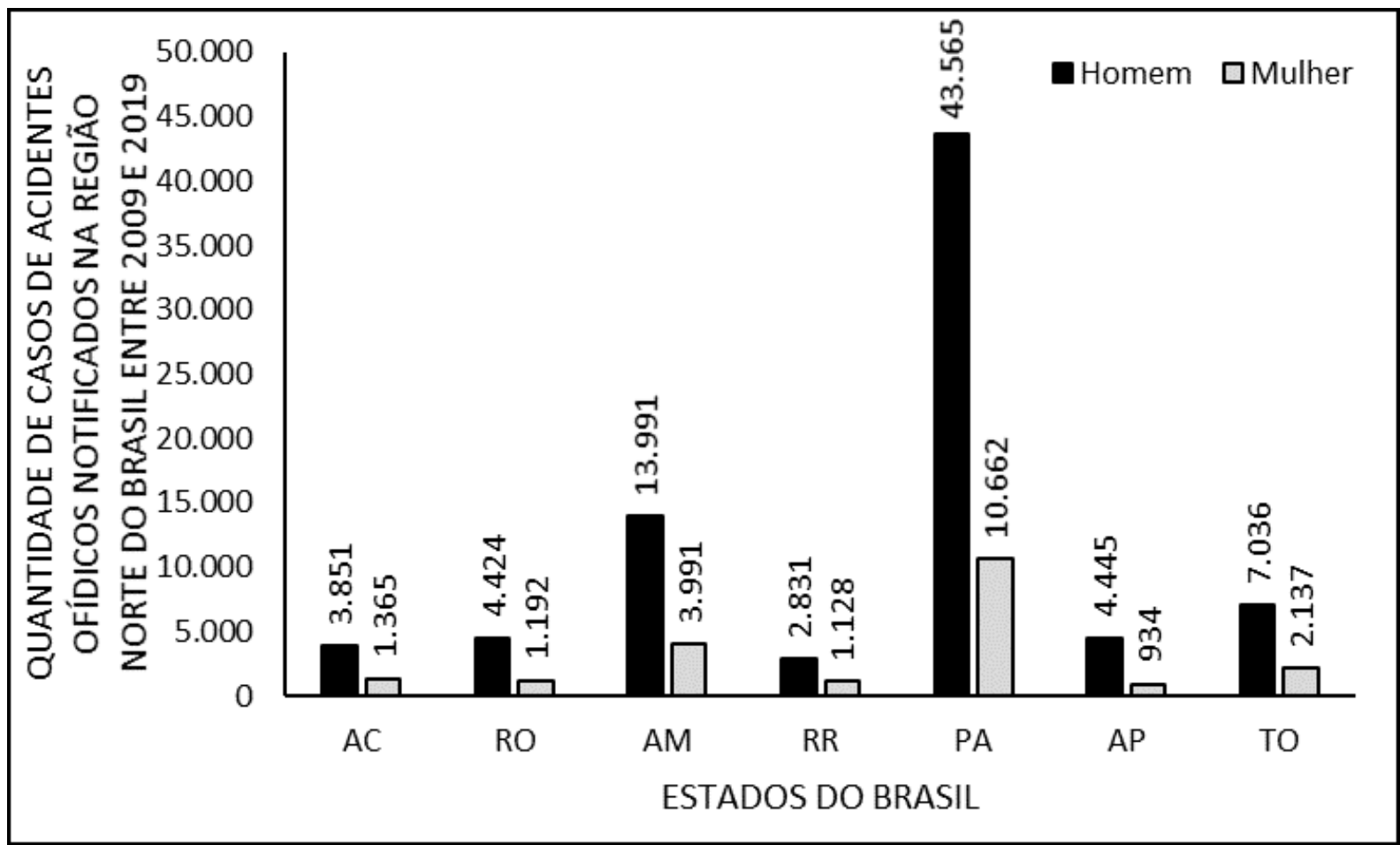


Quanto a distribuição percentual dos casos em relação à faixa etária acometida, houveram 15 casos sem a devida identificação (ignorado); 1200 casos com menores de 1 ano; 1.881 casos com pacientes entre 1 e 4 anos; 5.832 casos entre 5 e 9 anos; 10.299 com crianças de 10 a 14 anos, com o crescente aumento de casos para 11.872 em indivíduos de 15 a 19 anos. Atingindo o auge de 38.428 casos na faixa etária de 20 a 39 anos; apresentando 24.154 casos na faixa de 40 a 59 anos, com significativa queda para 3.275 casos dos 60 aos 64 anos; seguido de 2.153 casos entre os 65 e 69 anos; 1.983 acidentes entre pessoas de 70 a 79 anos e; 473 casos em maiores de 80 anos (figura 6).

Figura 6. Mostra a quantidade de casos de acidentes ofídicos na região Norte do Brasil entre os anos de 2009 e 2019, por faixa etária.

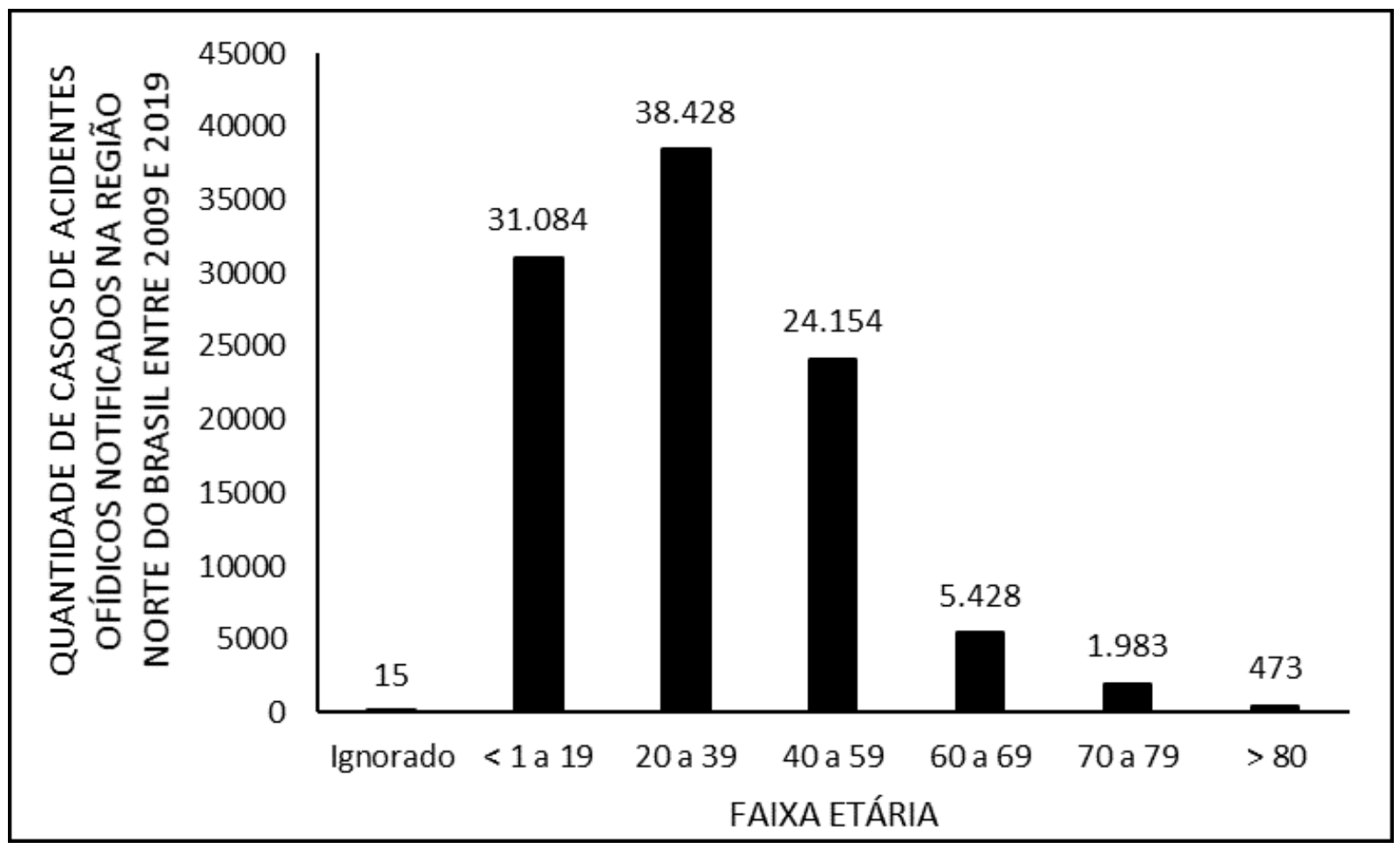

Com relação aos tipos de serpente envolvidos, aferiu-se que 6.255 não tiveram o tipo identificado (ignorado), enquanto que 82.832 foram atribuídos ao gênero Bothrops, 2.125 ao gênero Crotalus, 341 ao gênero Micrurus, 7.709 ao gênero Lachesis, e 2.303 foram identificadas como acidentes com serpentes não peçonhentas; conforme demonstrado na figura 7 . 
Figura 7. Mostra a quantidade de casos de acidentes ofídicos na região Norte do Brasil entre os anos de 2009 e 2019, por gêneros de ofídios.

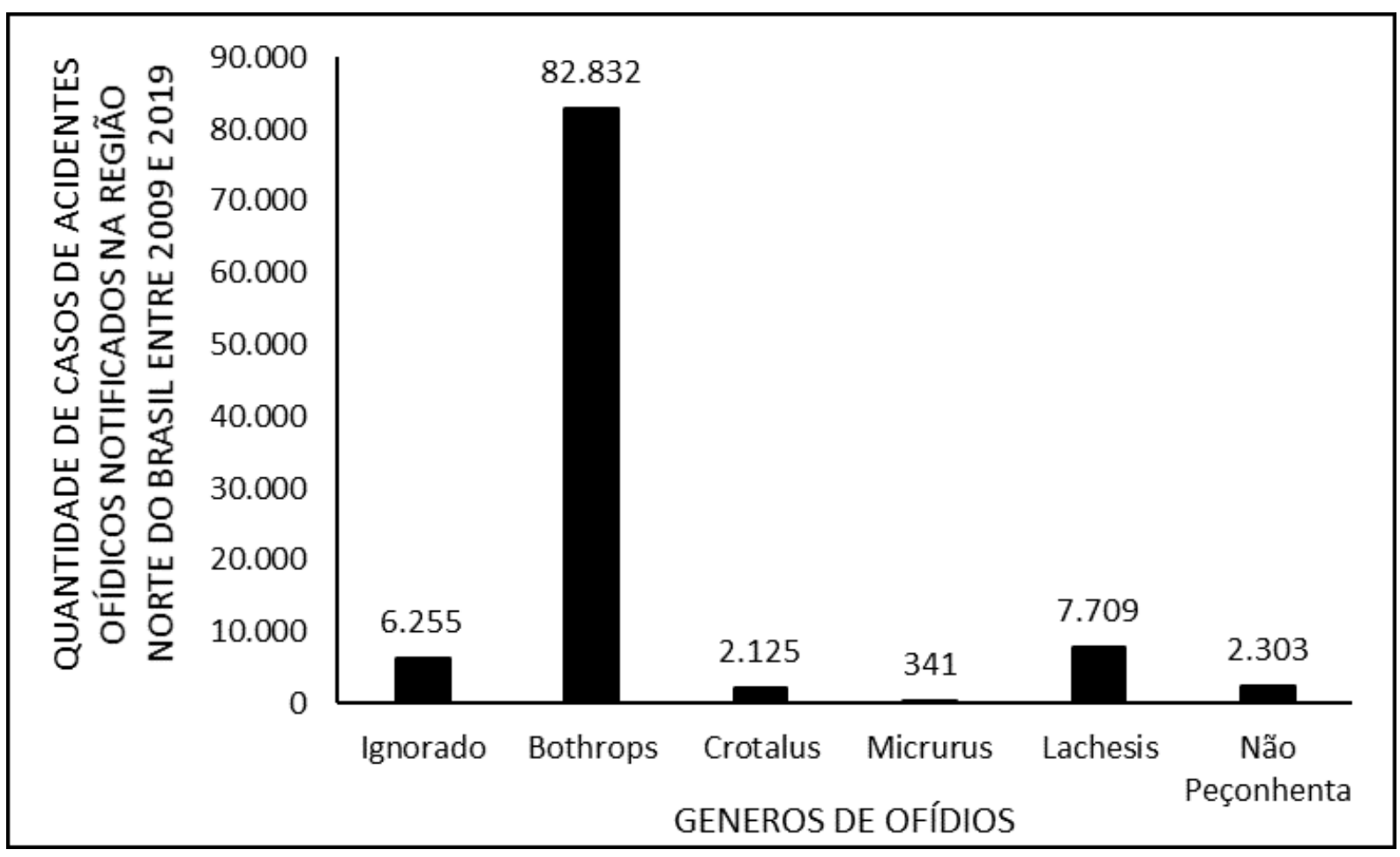

Em 5.831 fichas de notificação o tempo para atendimento não foi preenchido (ignorado); em 18.593 foi de até 1 hora; 31.560 pessoas levaram entre 1 e 3 horas; em 22.422 foi de 3 a 6 horas; em 10.730 foi de 6 a 12 horas; em 6.880 foi de 12 a 24 horas e; 5.549 pessoas demoraram 24 horas ou mais para conseguirem atendimento (figura 8). 
Figura 8. Mostra a quantidade de casos de acidentes ofídicos na região Norte do Brasil entre os anos de 2009 e 2019, segundo tempo para atendimento, em horas.

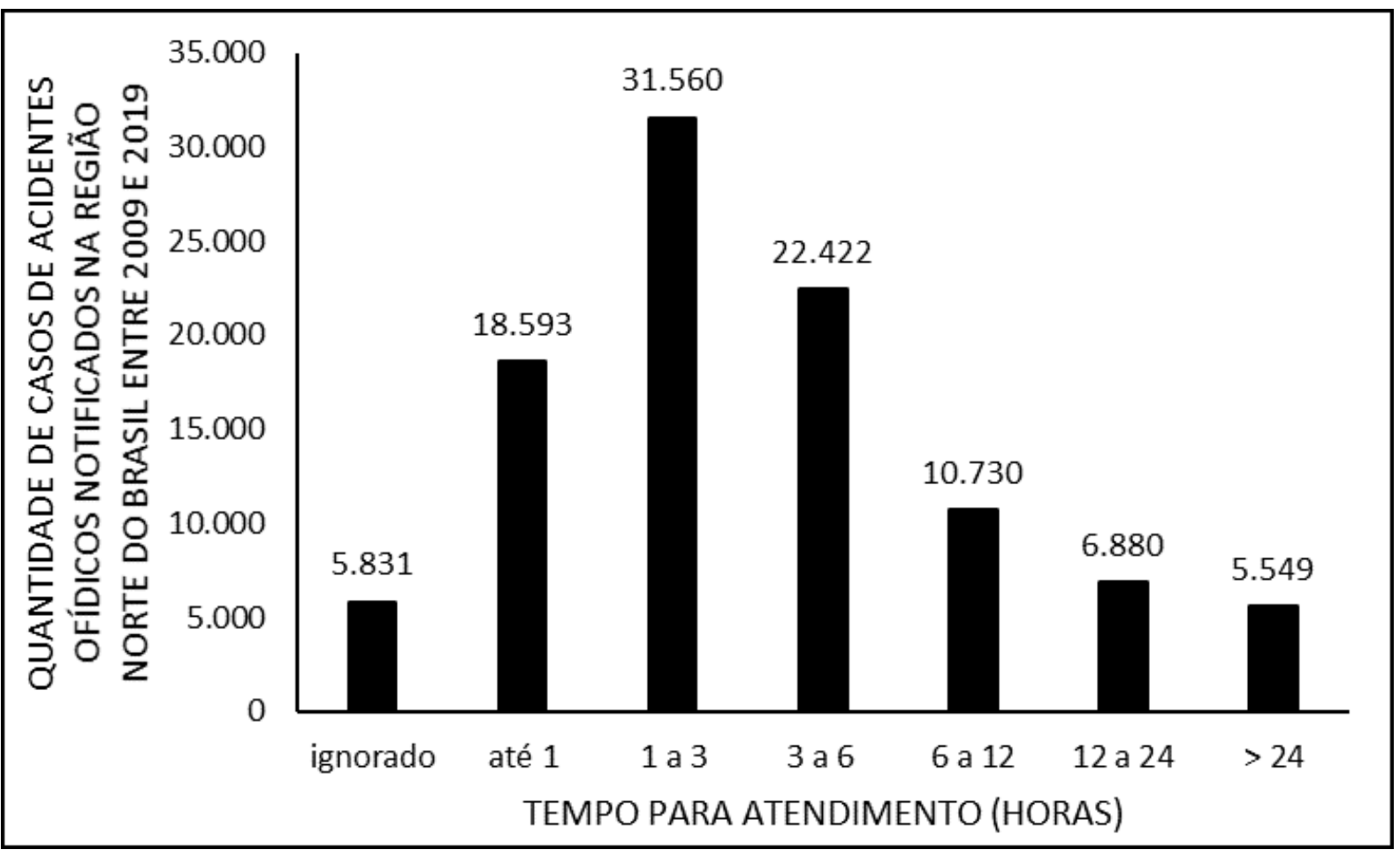

\section{DISCUSSÃO}

Segundo o Boletim Epidemiológico do Ministério da Saúde (BRASIL, 2019), os acidentes por animais peçonhentos no Brasil, constituem a segunda maior causa de envenenamento humano, sendo a primeira representada por intoxicação por uso de medicamentos. A magnitude desse problema está evidenciada no gráfico 1 que demonstra a distribuição anual dos 101.565 de casos registrados na Região Norte durante a década de 2009 a 2019, dos quais 465 pacientes foram a óbito, representando assim uma letalidade de $0,45 \%$.

É possível notar que, mesmo com esse elevado número de casos e a nítida relevância do agravo, os dados são, em grande parte, incompletos, devido à falha na identificação da serpente causadora do acidente e/ou no atendimento dos pacientes pela falta ou baixa qualidade das notificações, que apesar de obrigatórias no país, não refletem a realidade existente, o que torna dificultoso a real dimensão desse problema (MACHADO, 2018). 
Fato este evidenciado pelo gráfico 2, no qual é possível verificar que o Estado do Amazonas, com maior extensão e com grande área mata preservada representa apenas $17,7 \%$ dos casos notificados. Assim como BORGES et al. (1999) também constataram, afirmando ainda que essa subnotificação pode ser resultante, entre outros fatores, das dificuldades de acesso aos serviços de saúde dessa região.

Outro possível obstáculo, constatado por Machado e Bochner (2012) é a baixa importância dada pelos profissionais de saúde às notificações dos agravos que, apesar de obrigatórias e fundamentais para a saúde pública, afetando inclusive a distribuição de soro e a melhor utilização dos recursos públicos, ainda são vistas como mera atividade burocrática, sendo, por vezes, relegadas a segundo plano, e/ou realizadas por um funcionário administrativo, com o simples propósito de atender à exigência da apresentação de uma notificação ao sistema.

Os acidentes foram mais frequentes entre os meses de janeiro a maio (gráfico 3), coincidindo com os períodos de maior pluviosidade e temperatura, bem como o aumento da atividade agropecuária na Região Norte. Estudos indicam haver relação direta do aumento de acidentes ofídicos com a época destinada a atividade agrícola (PINHO et al., 2004; NASCIMENTO, 2000).

Esta hipótese tem sido sustentada também pelo fato que a precipitação pluviométrica elevaria os níveis das águas dos rios, fazendo com que as serpentes que habitam as regiões próximas dessas margens migrem à procura de terra firme, logo, com a diminuição desse espaço territorial, aumenta-se o contato com populações humanas, o que facilitaria a ocorrência dos acidentes (MORENO et al., 2005; PARDAL et al., 1995).

A distribuição entre os gêneros dos pacientes atendidos (gráficos 4 e 5) e a distribuição por faixa etária (gráfico 6) caracterizam o perfil dos acometidos por estes agravos. No presente estudo, houve maior frequência entre 20 a 39 e de 40 a 59 , acometendo, portanto, maioria de homens, em idade produtiva. 
Moreno et al. (2005) constatou que a maioria dos acidentes envolve pessoas do sexo masculino, trabalhadores rurais, de 10 a 29 anos, provavelmente, devido a maior frequência com que esse grupo desenvolve atividades, principalmente, na agricultura e no extrativismo. Logo, este segmento ocupacional estaria mais exposto às serpentes e, consequentemente, aos acidentes. Machado e Bochner (2012) corroboram com esses achados que constataram que os pacientes de origem rural, ou que relataram atividade agrícola, apresentam riscos aumentados de acidentes ofídicos, portanto, identificados como um grupo de alto risco. Dentre os principais fatores que definem esses acidentes, pode-se destacar a ligação com as atividades econômicas ligadas ao campo, floresta e águas, podendo assim ser classificado majoritariamente como acidente de trabalho (BRASIL, 2014).

A distribuição dos acidentes por gênero das serpentes é importante por auxiliar na indicação mais precisa do antiveneno a ser administrado e da conduta a ser tomada. Além de viabilizar o reconhecimento das espécies de relevância médica em âmbito regional (BRASIL, 2001).

Neste estudo, as serpentes do gênero Bothrops (82\%) apresentam o maior número de acidentes (82\%) seguidas pelas do gênero Lachesis (7\%) (gráfico 7). Assim como constatou o Borges et al. (1999), os resultados obtidos não diferem daqueles observados por outros autores no que se refere ao gênero da serpente Bothrops responsável pelo maior número de acidentes ofídicos com envenenamento.

Os acidentes ofídicos são classificados de acordo com o gênero da serpente, sendo nomeados Bothrops, Crotalus, Lachesis e Micrurus. Essa divisão tem essencial valor clínico, uma vez que os venenos encontrados nesses quatro grupos de serpentes possuem comportamentos distintos no paciente, sendo sua identificação, portanto, determinante na conduta e no seguimento do caso (BARRAVIERA, 1992).

A saber, estes gêneros relacionam-se, respectivamente, entre outras, às espécies popularmente conhecidas como: jararacas, jararacussu; cascavéis; surucucus; e corais-verdadeiras (MELGAREJO, 2003). Cada gênero apresenta um quadro clínico após o acidente, dependendo da quantidade de veneno inoculado. Os acidentes 
botrópicos e laquéticos geralmente apresentam dor, edema, equimose e eritema, bem como podem complicações locais, como: celulites, abcessos, síndrome compartimental e, que se não tratadas, podem evoluir para a amputação do membro (OTERO PATIÑO, 2009).

Nos acidentes crotálicos pode-se encontrar edema e parestesia, embora não costumem apresentar alterações locais significativas (AMARAL, 2001). São encontradas manifestações sistêmicas, como alterações renais, e neurológicas, como parestesia, ou até mesmo paralisia com progressão craniocaudal, iniciando com oftalmoplegia e ptose palpebral, o que pode ocasionar um quadro de insuficiência respiratória aguda, por meio da paralisia da musculatura respiratória (AMARAL, 2001; BRASIL, 2001).

Já os acidentes com as espécies do gênero Micrurus podem apresentar de manifestações locais leves como parestesia e dor de intensidade variável com ou sem irradiação, podendo estas até estar ausentes. Em caráter sistêmico pode ocorrer miastenia aguda com ptose palpebral e diminuição objetiva da força muscular, ainda sem sinais de paralisia em casos moderados. Em casos graves o paciente pode apresentar sinais de fraqueza muscular intensa e paralisia muscular que pode evoluir com paralisia respiratória aguda (BRASIL, 2014).

O tempo para atendimento dos acidentes ofídicos (gráfico 8) que no período analisado em sua maioria foi de até 3 horas após a picada, seguido pelo tempo de 6 a 12 horas após a picada. Observa-se também que pacientes vítimas de picada nos membros, que utilizam torniquetes, que foram atendidos com mais de seis horas do acidente, ou que receberam administração incorreta do soro antiofídico, apresentaram pior prognóstico (JORGE, RIBEIRO, 1990).

Uma importante orientação é quanto à procura de atendimento médico que deve ser o mais breve possível. Com relação ao atendimento das vítimas, o prognóstico geralmente é bom nos acidentes classificados como leves e moderados e nos pacientes atendidos nas primeiras seis horas após a picada (BRASIL, 2001). 


\section{CONCLUSÃO}

Constatou-se a relevância dos acidentes ofídicos, principalmente, na Região Norte do país, sendo que nos casos registrados ficou clara a relação do ofidismo com o período de chuvas, notando-se que nos meses de janeiro a maio há um aumento significativo no número de casos, correspondendo justamente aos períodos em que a pluviosidade está aumentada, quer seja pelo deslocamento das serpentes em busca de abrigo ou por coincidir com períodos de importante atividade agrícola.

Esta relação entre os acidentes ofídicos e a atividade agrária é tão relevante que este agravo poderia ser classificado como doença ocupacional. No presente estudo essa associação fica clara quando se percebe que a maioria dos acidentes ocorreram com pacientes do gênero masculino (78,9\%), e em idade produtiva (50\%) entre 20 e 59 anos.

O principal gênero de serpente relacionado aos acidentes ocorridos no presente estudo é Bothrops, representando $81,56 \%$ dos casos. Outro fator observado é que $49,38 \%$ dos pacientes foram atendidos até 3 horas após o acidente, o que é importante para um bom prognóstico, no entanto, 22,79\% ainda demoraram mais de 6 horas para serem atendidos, o que diminui as chances de um desfecho favorável.

Ressalta-se ainda que apesar do significativo número de casos relatados, nem sempre esse agravo é registrado, devido a essa subnotificação o acesso aos dados fidedignos fica comprometido. Além disso, a falta de procura de atendimento especializado potencialmente leva a um pior prognostico do quadro, decorrente muitas vezes de condutas equivocadas como uso de torniquetes, chás e medidas caseiras equivocadas. Reafirmando assim a necessidade de cuidados médicos e notificação adequada. 


\section{REFERÊNCIAS}

AMARAL, C.F.S. et al. Manual de de diagnóstico e tratamento de acidentes por animais peçonhentos. 2 ed. Brasília. Ministério da Saúde, Fundação Nacional de Saúde, 2001.

BARRAVIERA, B. $O$ ensino dos acidentes por animais peçonhentos nas escolas médicas brasileiras. Revista da Sociedade Brasileira de Medicina Tropical 25(3): 203-204, jul-set, 1992.

BORGES, C. C.; SADAHIRO, M.; SANTOS, M. C. Aspectos epidemiológicos e clínicos dos acidentes ofídicos ocorridos nos municípios do Estado do Amazonas. Rev. Soc. Bras. Med. Trop., Uberaba, v. 32, n. 6, p. 637-646, Dec. 1999

Disponível em:<http://www.scielo.br/scielo.php?script=sci_arttext\&pid=S0037$86821999000600005 \&$ Ing=en\&nrm=iso>. Acesso em 18 jan 2020.

BRASIL. Ministério da Saúde. Manual de diagnóstico e tratamento de acidentes por animais peçonhentos. Brasília: Fundação Nacional de Saúde; 2001.

BRASIL. Ministério da Saúde. PROTOCOLO CLÍNICO. Acidente por serpente da família Elapidae, gêneros Micrurus e Leptomicrurus "Coral verdadeira". 2014. Disponível em: http://www.saude.gov.br/images/pdf/2014/marco/13/Protocolo-clinicoAcidente-por-serpente-da-familia-Elapidae.pdf. Acesso em 11 jun 2020.

BRASIL. Ministério da Saúde. Boletim Epidemiológico: Acidentes de trabalho por animais peçonhentos entre trabalhadores do campo, floresta e águas, Brasil 2007 a 2017. Secretaria de Vigilância em Saúde; 2019.

GUTIÉRREZ, J.M.; CALVETE, J.J.; HABIB, A. G.; HARRISON, R.A.; WILLIAMS, D. J.; WARREL, D. A. Snakebite envenoming. Nature Rewies: Disease Primers, San Jose, Costa Rica, v. 3, n. 17063, 14 set 2017. DOI https://doi.org/10.1038/nrdp.2017.63. Disponível em :https:www.nature.com/articles/nrdp201763. Acesso em 02 de fev 2020 
JORGE, M.T.; RIBEIRO, L.A. Acidentes por serpentes peçonhentas do Brasil. Rev Assoc Med Bras.; 36(2):66-77; 1990.

MACHADO C.; BOCHNER, R. A informação dos acidentes crotálicos no Estado do Rio de Janeiro, 2001 a 2010. Gaz Med Bahia ;82(1):78-84; 2012.

MACHADO, C. Acidentes ofídicos no Brasil: da assistência no município do Rio de Janeiro ao controle da Saúde Animal Instituto produtor de soro antiofídico; Rio de Janeiro; 2018.

MELGAREJO. A. R. 2003. Serpentes peçonhentas do Brasil. Pp. 33-61 In: Animais peçonhentos no Brasil: biologia, clínica e terapêutica dos acidentes. Cardoso et al. (Orgs.). Sarvier, São Paulo - SP.

MORENO, E.; ANDRADE, M. Q.; SILVA, R. M. L da; NETO, J. T. Características clínicoepidemiológicas dos acidentes ofídicos em Rio Branco, Acre. Rev. Soc. Bras. Med. Trop., Uberaba , v. 38, n. 1, p. 15-21, Feb. 2005 . Disponível em: $<$ http://www.scielo.br/scielo.php?script=sci_arttext\&pid=S0037$86822005000100004 \&$ Ing=en\&nrm=iso $>$. Acesso em 18 jun 2020.

NASCIMENTO, S. P. Aspectos epidemiológicos dos acidentes ofídicos ocorridos no Estado de Roraima, Brasil, entre 1992 e 1998. Cad. Saúde Pública, Rio de Janeiro , v. 16, n. 1, p. 271-276, Jan. 2000 . Disponível em: <http://www.scielo.br/scielo.php?script=sci_arttext\&pid=S0102311X2000000100031\&lng=en\&nrm=iso>. Acesso em 18 jun 2020.

OTERO-PATINOO, R. Epidemological, clinical and therapeutic aspects of Bothrops asper bites. Toxicon, v.54, p 998-1101, 2009.

PARDAL, P. P. O. Aspectos epidemiológicos de 465 acidentes atendidos no HUJBB-Belém, Pará, no período de 1993-1994. In: Congresso da Sociedade Brasileira de Medicina Tropical, 31, São Paulo, 1995. livro de Resumos, resumo 340, 1995, p. 170. 
PINHO, F..M.O.; WHO, P.I.D. Ofidismo. Rev. Assoc. Med. Bras. 2001; 47(1):24-9.

PINHO, F.M.O; OLIVEIRA, E.S.; FALEIROS, F. Acidente ofídico no estado de Goiás. Rev. Assoc. Med. Bras., São Paulo, v. 50, n. 1, p. 93-96, 2004. Disponível em:<http://www.scielo.br/scielo.php?script=sci_arttext\&pid=S0104$42302004000100043 \&$ Ing=en\&nrm=iso >. Acesso em 16 jun 2020.

WEISS, M.B.; PAIVA, J.W.S. Acidentes com animais peçonhentos.1 Ed. Rio de Janeiro- RJ: Thieme Revinter Publicações Ltda, 2017. p. 36-37.

WHO. WORLD HEALTH ORGANIZATION (Geneva, Switzerland). Snakebite envenoming: A strategy for prevention and control. Geneva: [s. n.], 2019. 55 p. E-book.

Enviado: Setembro, 2020.

Aprovado: Setembro, 2020. 